\title{
Ketogenic Diet Metabolites Reduce Firing in Central Neurons by Opening $\mathrm{K}_{\mathrm{ATP}}$ Channels
}

\author{
Weiyuan Ma, Jim Berg, and Gary Yellen \\ Department of Neurobiology, Harvard Medical School, Boston, Massachusetts 02115
}

\begin{abstract}
A low-carbohydrate ketogenic diet remains one of the most effective (but mysterious) treatments for severe pharmacoresistant epilepsy. We have tested for an acute effect of physiological ketone bodies on neuronal firing rates and excitability, to discover possible therapeutic mechanisms of the ketogenic diet. Physiological concentrations of ketone bodies ( $\beta$-hydroxybutyrate or acetoacetate) reduced the spontaneous firing rate of neurons in slices from rat or mouse substantia nigra pars reticulata. This region is thought to act as a "seizure gate," controlling seizure generalization. Consistent with an anticonvulsant role, the ketone body effect is larger for cells that fire more rapidly. The effect of ketone bodies was abolished by eliminating the metabolically sensitive $K_{A T P}$ channels pharmacologically or by gene knock-out. We propose that ketone bodies or glycolytic restriction treat epilepsy by augmenting a natural activity-limiting function served by $\mathrm{K}_{\mathrm{ATP}}$ channels in neurons.
\end{abstract}

Key words: epilepsy; ketogenic diet; $\mathrm{K}_{\mathrm{ATP}}$ channels; substantia nigra pars reticulata; glycolysis; anticonvulsant treatment

\section{Introduction}

Approximately one-third of people with epilepsy cannot achieve effective seizure control with anticonvulsant medications. One very effective alternative is dietary treatment. The ketogenic diet, introduced in the 1920s (Wilder, 1921; Peterman, 1924; Freeman et al., 2000; Bailey et al., 2005), is a low-carbohydrate, high-fat regimen on which $\sim 30 \%$ of patients become seizure free, and $\sim 60 \%$ experience significant benefit (Thiele, 2003). This effectiveness is seen across different seizure types and seizure etiology, suggesting that rather than targeting specific causes of seizure [aside from certain metabolic disorders (Wang et al., 2005)], the diet enhances the activity of an endogenous antiseizure mechanism.

On a ketogenic diet, the "ketone bodies" acetoacetate and $\beta$-hydroxybutyrate circulate at millimolar concentrations in the blood and provide an alternative fuel source to tissues, including the brain. The onset of seizure control is typically slow, probably reflecting the induction of the transporters and enzymes required for effective utilization of ketone bodies by the brain (Pan et al., 2001; Cullingford et al., 2002). In contrast, seizure protection is lost quite quickly when the ketogenic diet is "broken" by a supply of sugar. This has been seen both experimentally (Huttenlocher, 1976) and anecdotally: with an infusion of sugar, or when patients "cheat" on the diet (e.g., by having a candy bar), seizure

Received Jan. 11, 2007; revised Feb. 13, 2007; accepted Feb. 22, 2007.

This work was supported by a Harvard Medical School-Howard Hughes Medical Institute seed grant (G.Y.), a Neuroscience of Brain Disorders Award from the McKnight Endowment Fund for Neuroscience (G.Y.), a National Research Service Award from the National Institutes of Health (J.B.), and a grant from the Ellison Foundation (G.Y.) We thank Heidi Pfeifer and Dr. Elizabeth A. Thiele for teaching us about the ketogenic diet and Geoffrey Tanner for valuable discussions and comments on this manuscript. We are also grateful to Drs. Bruce Bean, Michael Do, Marco Martina, and Wade Regehr for help and advice. Kir6.2 knock-out mice were generously provided by Drs. S. Seino and C. G. Nichols; we thank Tatiana Abramson for expert technical assistance in genotyping the mice.

Correspondence should be addressed to Dr. Gary Yellen, Department of Neurobiology, Harvard Medical School, 220 Longwood Avenue, Boston, MA 02115. E-mail: gary_yellen@hms.harvard.edu.

DOI:10.1523/JNEUROSCI.0132-07.2007

Copyright $\odot 2007$ Society for Neuroscience $\quad$ 0270-6474/07/273618-08\$15.00/0 protection is lost in the course of tens of minutes. This rapid loss of protection coinciding with a change in energy source suggests an acute physiologic mechanism that responds rapidly to ketone body versus carbohydrate metabolism.

We tested the acute effect of ketone bodies on neuronal firing rates and excitability, to discover possible therapeutic mechanisms of the ketogenic diet. We recorded from GABAergic neurons of the substantia nigra pars reticulata $(\mathrm{SNr})$, because their regular spontaneous firing is ideal for study and because they act as a "gate" for seizures (Iadarola and Gale, 1982; McNamara et al., 1984; Gale, 1986; Depaulis et al., 1994). Inhibition of these neurons in vivo can make it more difficult to produce seizures, even when the primary stimulus for the seizure is elsewhere in the brain. Very rapid firing of $\mathrm{SNr}$ neurons in vivo can precede generalized seizure onset, and reduction in firing sometimes precedes the termination of a generalized seizure (Deransart et al., 2003).

These neurons also contain an excellent candidate system for the control of neuronal excitability by metabolism: ATP-sensitive $\mathrm{K}^{+}$channels ( $\mathrm{K}_{\text {ATP }}$ channels) (Karschin et al., 1997; Richards et al., 1997). Best-known for their role in controlling insulin secretion from pancreatic $\beta$-cells (Ashcroft and Gribble, 1999), $\mathrm{K}_{\text {АTP }}$ channels are also widely expressed in central neurons. Under typical recording conditions, they appear to be mostly shut, although they can be activated by metabolic insult (Yamada et al., 2001) or coincident with cellular activity (Haller et al., 2001). We suspected that $\mathrm{K}_{\text {АTP }}$ channels play a role in the ketogenic diet or in the actions of ketone bodies, and we tested for this with channel inhibitors and with a knock-out mouse for the gene encoding Kir6.2, a principal channel-forming subunit of $\mathrm{K}_{\mathrm{ATP}}$ channels.

\section{Materials and Methods}

Coronal midbrain slices of $250 \mu \mathrm{m}$ thickness were cut from the brains of 13- to 15-d-old rats (Sprague Dawley; Harlan, Indianapolis, IN) or mice, 


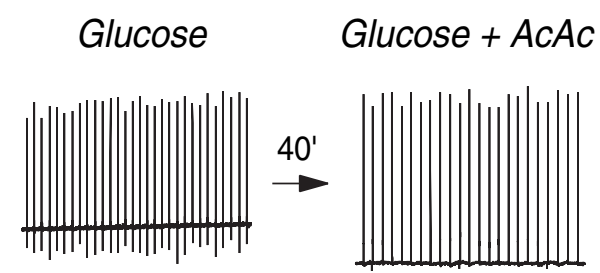

$1 \mathrm{sec}$

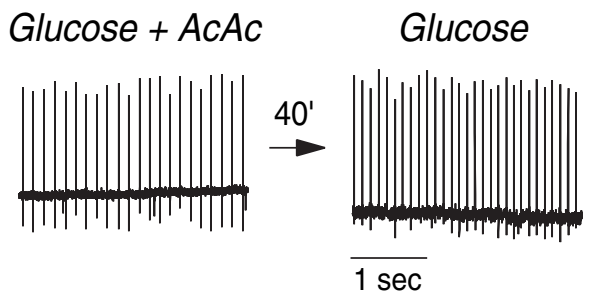

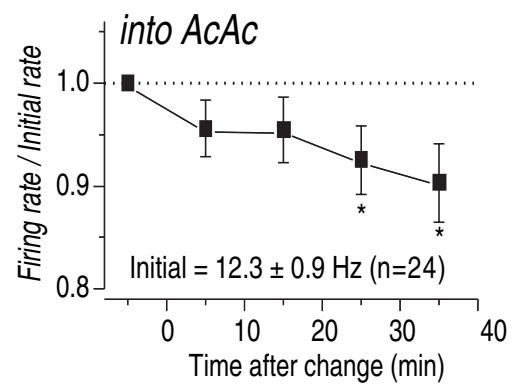

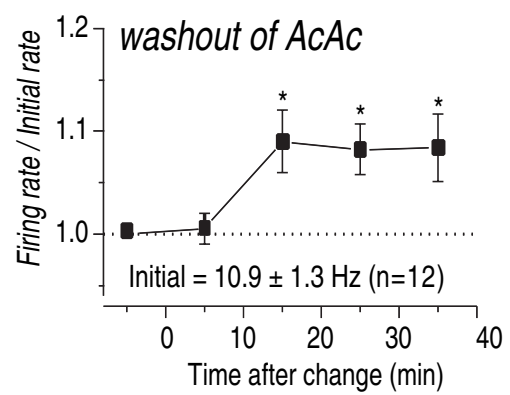

Figure 1. Ketone body application slows the firing of SNr neurons. Effect of acetoacetate addition (top row) or removal (bottom row) on firing of individual neurons. Left, Extracellular loose-patch recordings of action currents. Right, Summary data normalized to the initial firing rate of each cell. The control solution contained $12 \mathrm{~mm}$ glucose, and the experimental solution had $12 \mathrm{~mm}$ glucose plus $2 \mathrm{~mm}$ acetoacetate. ${ }^{*} p<0.05$.

using a vibrating tissue slicer (Vibratome, St. Louis, MO). Rats or mice were anesthetized by halothane before decapitation and removal of the brain. All procedures involving animals were approved by the Harvard Medical Area Standing Committee on Animals. Mouse strains used were wild-type BL6 or C3H mice (Charles River Laboratories, Wilmington, MA), or Kir6.2 knock-out mice (Seino et al., 2000) or their heterozygous littermates, maintained by backcrosses with wild-type BL6.

After cutting, slices were incubated at $37^{\circ} \mathrm{C}$ for $20 \mathrm{~min}$ in solution containing the following (in mM): $87 \mathrm{NaCl}, 25 \mathrm{NaHCO}_{3}, 25 \mathrm{D}$-glucose, 75 sucrose, $2.5 \mathrm{KCl}, 1.25 \mathrm{NaH}_{2} \mathrm{PO}_{4}, 0.5 \mathrm{CaCl}_{2}$, and $7 \mathrm{MgCl}_{2}$, bubbled with $95 \% \mathrm{O}_{2}$ and $5 \% \mathrm{CO}_{2}$. Afterward, slices were moved to a recording solution and bubbled with $95 \% \mathrm{O}_{2}$ and $5 \% \mathrm{CO}_{2}$ at $37^{\circ} \mathrm{C}$ for another $40 \mathrm{~min}$, then stored at room temperature for $0-2 \mathrm{~h}$ before use. All recording solutions contained (in mM) $25 \mathrm{NaHCO}_{3}, 12$ D-glucose, $2.5 \mathrm{KCl}, 1.25$ $\mathrm{NaH}_{2} \mathrm{PO}_{4}, 2 \mathrm{CaCl}_{2}$, and $1 \mathrm{MgCl}_{2}$. Standard modified artificial CSF (ACSF) solution contained also $131.5 \mathrm{~mm} \mathrm{NaCl}$; R- $\beta$-hydroxybutyrate $(\mathrm{R}-\beta \mathrm{HB})$ solution contained $129.5 \mathrm{~mm} \mathrm{NaCl}, 2 \mathrm{~mm} \mathrm{NaOH}$, and $2 \mathrm{~mm}$ R- $\beta$-hydroxybutyric acid (Kanto Chemical, Tokyo, Japan); AcAc solution contained $129.5 \mathrm{~mm} \mathrm{NaCl}$ and $2 \mathrm{~mm}$ Na-acetoacetate. $\mathrm{Na}^{+}$acetoacetate was prepared from $\mathrm{Li}^{+}$-acetoacetate (Sigma-Aldrich, St. Louis, MO) by ion exchange on Dowex 50x8-200 and quantitated by OD at $254 \mathrm{~nm}$ (Hall, 1962).

During recording, the solution supply was constantly bubbled with 95\% $\mathrm{O}_{2}$ and $5 \% \mathrm{CO}_{2}$ and delivered through a flow-through heater (Warner Instruments, Hamden, CT) at a temperature of $33-34^{\circ} \mathrm{C}$. Standard cell-attached patch recording methods were used, with loose seals (several hundred megaohms), and action currents were analyzed by computer using a homemade procedure in Igor (Wavemetrics, Lake Oswego, OR).

Experiments were done in young animals [postnatal day 13 (P13) to $\mathrm{P} 15]$, because before the time of weaning, rodents are essentially consuming a high-fat, low-carbohydrate diet comparable with a ketogenic diet (Nehlig, 1999). The enzymes for ketone body metabolism are therefore already expressed at high levels, permitting an acute effect of ketone bodies. The ketone body concentrations used here (1-2 mM; 2 mM unless stated otherwise) were comparable with or less than the reported plasma level in children after 1 month of a ketogenic diet (Huttenlocher, 1976) ( $\beta$-hydroxybutyrate, $4.8 \pm 1 \mathrm{~mm}$; acetoacetate, $1.8 \pm 0.3 \mathrm{~mm}$ ), and at the low end of the concentration range used for in vitro studies (Izumi et al.,
1998; Thio et al., 2000). They are fivefold to sevenfold higher than the CSF concentrations reported for children on the ketogenic diet (Huttenlocher, 1976; Nordli and DeVivo, 1997) ( $\beta$-hydroxybutyrate, $\sim 0.4 \mathrm{~mm}$; acetoacetate, $\sim 0.3 \mathrm{~mm}$; and glucose, $\sim 3.2 \mathrm{~mm}$ ). However, we found that long-term stable recordings from acute, superfused rat brain slices require significantly higher [glucose] than the nominal CSF concentration, which we suspect is because of the relatively poor delivery produced by superfusion compared with in vivo capillary perfusion. By this comparison, the ketone body concentrations used here seem reasonably physiological (Thio et al., 2000). Glucose concentration (12 mM) was typical for in vitro superfused brain slice preparations. Although blood glucose is somewhat depressed in humans on the diet, it seemed most conservative to maintain glucose at a constant level when adding ketone bodies. Pilot experiments with a lower concentration of glucose $(5 \mathrm{~mm})$ did not give different results from those reported here.

Most experiments were done and analyzed by an investigator blind to the experimental condition and to the animal genotype. Results are reported as mean \pm SEM unless otherwise noted.

\section{Results \\ Reversible, stereoselective slowing of SNr GABAergic neuron firing by ketone bodies}

We measured the spontaneous firing rate of SNr GABAergic neurons in rat or mouse brain slices using loose-patch cell-attached recordings of action currents. Fast excitatory and inhibitory synaptic inputs were blocked by including $1 \mathrm{~mm}$ kynurenic acid and $0.1 \mathrm{~mm}$ picrotoxin in the ACSF bathing the slice. The GABAergic neurons within $\mathrm{SNr}$ were chosen for their intermediate size and were identified by their very brief action currents $(\sim 0.5 \mathrm{~ms})$ and highly regular firing, which are characteristic of the GABAergic neurons and quite distinct from the properties of the dopaminergic neurons in SNr or SN pars compacta (Richards et al., 1997). Under control conditions (12 mM glucose, $33-34^{\circ} \mathrm{C}$ ), $\mathrm{SNr}$ GABAergic neurons in rat brain slices fired at $11.7 \pm 4.8 \mathrm{~Hz}$ (mean $\pm \mathrm{SD} ; n=126$ ), comparable with previous reports (Stanford and Lacey, 1996; Richards et al., 1997).

When the ketone body acetoacetate was applied (in the constant presence of glucose), the firing of individual neurons measured in longitudinal recordings was typically reduced, by an average of $\sim 10 \%$ (Fig. 1). This slowing took place and then stabilized over a period of $\sim 15-30 \mathrm{~min}$ of acetoacetate application. This was not attributable to rundown of the neurons, which were typically very stable; in fact, we found that a reverse switch, from ACSF containing acetoacetate to ACSF containing only glucose, produced faster firing over approximately the same time period (Fig. 1).

We confirmed this effect using population samples of neuronal firing, before and after ketone body applications, on many brain slices (on each slice, we recorded from 15 neurons both before application and after $30 \mathrm{~min}$ of application). A similar effect was seen for the other major circulating ketone body, the $\mathrm{R}$-stereoisomer of $\beta$-hydroxybutyrate, but not for the enantiomer S- $\beta \mathrm{HB}$ (supplemental Fig. 1, available at www.jneurosci.org as supplemental material), which should be transported into neurons via the monocarboxylate transporter (like R- $\beta \mathrm{HB}$ ), but 

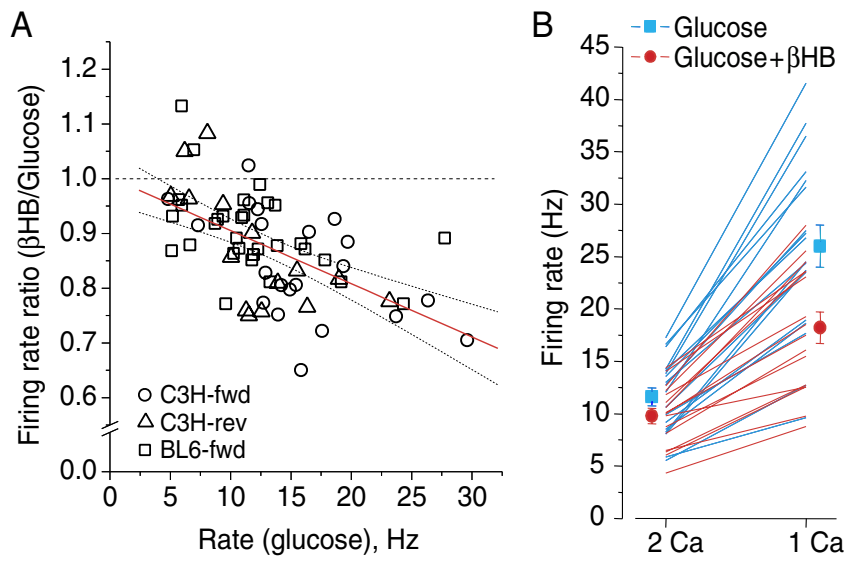

Figure 2. Ketone body effect is larger at higher firing rates. $\boldsymbol{A}$, With natural variation in initial firing rates, the reduction in firing rate is larger for faster initial rates. Regression line and $95 \%$ confidence interval lines are shown; regression is ratio $=1-0.0097 \times$ rate $(\mathrm{Hz})$. Slope differs from zero with $p<0.0001$. Data points are shown for glucose-to- $\beta \mathrm{HB}$ switches for cells from $\mathrm{BL6}$ (BL6-fwd) and $\mathrm{C} 3 \mathrm{H}$ (C3H-fwd) and for reverse switches in $\mathrm{C} 3 \mathrm{H}$ (C3H-rev). Each group individually has a significant correlation, with $p<0.025$ (Spearman). $\boldsymbol{B}$, In the presence of $\beta H B$, neurons are more resistant to higher firing in reduced-Ca ${ }^{2+}$ ACSF. Individual cells in BL6 slices were recorded at baseline, in the indicated condition, and then exposed for $5 \mathrm{~min}$ to reduced$\mathrm{Ca}^{2+}$ ACSF (1 mm total $\mathrm{CaCl}_{2}$ ). Each line represents the response of an individual cell; symbols give the mean and SEM of the firing rate for each group and condition.

not metabolized (Webber and Edmond, 1977; Carpenter and Halestrap, 1994; Jackson and Halestrap, 1996). The ketone bodyinduced reduction in firing of $\sim 10-20 \%$ was seen also in longitudinal recordings on individual SNr GABAergic neurons in several strains of mice, including BL6 and $\mathrm{C} 3 \mathrm{H}$.

\section{Greater slowing is observed for faster-firing neurons}

Is this relatively small effect of ketone bodies on neuronal firing a possible contributor to the anticonvulsant mechanism of the ketogenic diet? Many anticonvulsant drugs exhibit "use dependence," which makes their effects more prominent at high firing rates (Macdonald and Kelly, 1995). We examined our many longitudinal recordings of the $\beta \mathrm{HB}$ effect to look for a correlation between the firing rate of a cell under control conditions (glucose alone), which varies naturally over a substantial range, and the magnitude of the $\beta \mathrm{HB}$ effect (firing rate in glucose plus $\beta \mathrm{HB}$ as a fraction of the firing rate in glucose alone) (Fig. $2 A$ ). We found a strong correlation between faster firing and a larger $\beta \mathrm{HB}$ effect $[\sim 1 \%$ per $\mathrm{Hz}$ (see Fig. 2 legend)]. The effects did not result from greater rundown of faster-firing cells, as the reverse switches from $\beta \mathrm{HB}$ to glucose alone fit the same pattern.

To test more directly for the effect of faster firing on the magnitude of the ketone body effect, we used a brief challenge with low $\mathrm{Ca}^{2+}$ ACSF to increase the firing rate of neurons either in glucose alone or with $\beta \mathrm{HB}$ (Fig. $2 \mathrm{~B}$ ). In glucose alone, perfusion of low $\mathrm{Ca}^{2+} \mathrm{ACSF}$ increased the firing rate by 2.24 -fold $( \pm 0.15)$, whereas in the presence of ketone bodies, the average increase was only 1.84-fold ( \pm 0.09 ; different from glucose with $p<0.01$ ). In other words, in the presence of $\beta \mathrm{HB}$, the neurons were more resistant to a challenge that causes them to fire faster. On these samples of neurons, the firing rate of the 16 neurons in $\beta \mathrm{HB}$ was only $\sim 16 \%$ lower than that of the 18 neurons in glucose when measured in normal $\mathrm{Ca}^{2+}$, but for the same neurons, the firing rate when challenged with low $\mathrm{Ca}^{2+}$ was more substantially lower in $\beta \mathrm{HB}(\sim 32 \%$; $p<0.01)$ than with glucose alone.

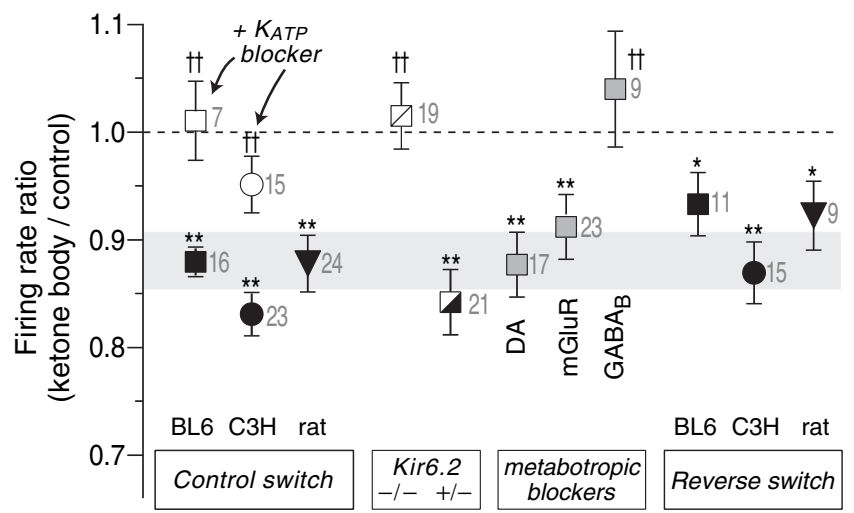

Figure 3. Ketone body effects on firing rate and their dependence on $\mathrm{K}_{\text {ATP }}$ channels and $\mathrm{GABA}_{B}$ receptors. For each condition, the firing rate of many individual cells was monitored for 30 - $40 \mathrm{~min}$ after a metabolic switch, and the firing rate for the final $5 \mathrm{~min}$ was normalized to the firing rate before the switch. The metabolic switch was from glucose to glucose plus $\beta \mathrm{HB}$ (2 $\mathrm{mm}$ ) for all except rat, which was glucose to glucose plus AcAc ( $2 \mathrm{~mm})$; the final three symbols indicate results for the reverse switch from ketone body containing solution to glucose alone, plotting the initial rate divided by the final rate. The shaded zone indicates the $95 \%$ confidence interval for the forward switch in $\beta \mathrm{HB}$ on BL 6 cells. The $\mathrm{K}_{\text {ATP }}$ blocker was tolbutamide, present at $200 \mu \mathrm{m}$ for at least $10 \mathrm{~min}$ before the switch $(300 \mu \mathrm{m}$ for $\mathrm{C} 3 \mathrm{H}$ slices). The metabotropic blockers (also present for at least 10 min before the switch; BL6, shaded squares) were the dopamine receptor antagonist fluphenazine ( $1 \mu \mathrm{M})$, the mGluRantagonists CPPG $(200 \mu \mathrm{M})$ and CPCCOEt $(100 \mu \mathrm{M})$, and the GABA $A_{B}$ antagonist CGP55845 $(2 \mu \mathrm{M}) .{ }^{*} p<0.05,{ }^{* *} p<0.01$ for difference from 1 by Student's $t$ test; ${ }^{\dagger+} p<0.01$ for difference from the corresponding control group, by a Mann-Whitney $U$ test. Numerals next to data points indicate number of experiments.

\section{$\mathrm{K}_{\mathrm{ATP}}$ channels are required for the ketone body effect}

Because $\mathrm{K}_{\mathrm{ATP}}$ channels are the best-characterized connection between metabolism and neuronal excitability, we examined their role in the ketone body-induced slowing. We first tested the effects of simply applying sulfonylurea inhibitors on control firing rates. Application of glibenclamide (100 nM) or tolbutamide (200 $\mu \mathrm{M})$ to SNr GABAergic neurons made very little difference in firing rate, suggesting that these channels may be completely closed under ordinary recording conditions. However, activation of $\mathrm{K}_{\mathrm{ATP}}$ channels with the $\mathrm{K}^{+}$channel opener diazoxide $(200 \mu \mathrm{M})$ typically produced slowing or even silencing of SNr neurons (firing rate/control $=51 \pm 26 \%$, rat; mean $\pm \mathrm{SD} ; n=11$ ).

Blockade of $\mathrm{K}_{\mathrm{ATP}}$ channels with either of the sulfonylurea inhibitors prevented the slowing of firing that was otherwise seen with ketone body wash-in (Fig. 3; supplemental Fig. 1, available at www.jneurosci.org as supplemental material), suggesting an important role for $\mathrm{K}_{\mathrm{ATP}}$ channels in the effect. We were concerned, however, that some of the effects of the sulfonylureas might not be on the well described $\mathrm{K}_{\mathrm{ATP}}$ channels present in the surface membrane of $\mathrm{SNr}$ and other central neurons, but rather on mitochondrial $\mathrm{K}_{\mathrm{ATP}}\left(\right.$ mitoK $_{\mathrm{ATP}}$ ) channels (Jaburek et al., 1998). These channels are more controversial, and many of the phenomena attributed to mitoK $_{\mathrm{ATP}}$ channels are suspected to be nonspecific effects of diazoxide and the sulfonylurea drugs (Hanley et al., 2002). The molecular basis of mitochondrial $\mathrm{K}_{\mathrm{ATP}}$ is also not known. Surface membrane $\mathrm{K}_{\mathrm{ATP}}$ channels in $\mathrm{SNr}$ neurons (and in many other cells, including pancreatic $\beta$ cells) consist of heterooctamers including four Kir6.2 pore-forming subunits coassembled with four SUR1 sulfonylurea-receptor subunits (Liss et al., 1999). It has been shown that in knock-out mice lacking the gene that codes for the Kir6.2 subunit (Seino et al., 2000), the pharmacological phenomena associated with mito $K_{\mathrm{ATP}}$ channels are still present, but the surface $\mathrm{K}_{\mathrm{ATP}}$ channels in 


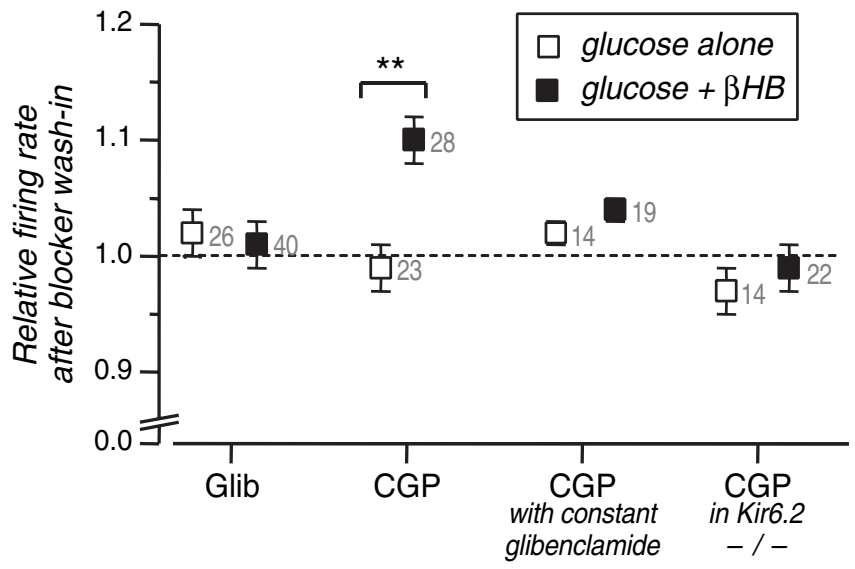

Figure 4. Ability of $K_{A T P}$ and $G A B A_{B}$ inhibitors to reverse an established effect of $\beta H B$. The specified blockers were added to slices previously incubated in $12 \mathrm{~mm}$ glucose (open symbols) or $12 \mathrm{~mm}$ glucose plus $2 \mathrm{~mm} \beta \mathrm{HB}$ (closed symbols), and the change in normalized firing rate is shown (5 min averages, before application and $10 \mathrm{~min}$ after). The GABA ${ }_{\mathrm{B}}$ blocker CGP55845 produces an increase in firing rate in $\beta \mathrm{HB}$ but not if $\mathrm{K}_{\mathrm{ATP}}$ channels were blocked by application of glibenclamide (Glib) before $\beta H B$ or were absent in Kir6.2 knock-out animals. ${ }^{* *} p<0.01$ by Mann-Whitney $U$ test. Numerals next to data points indicate number of experiments.

$\beta$ cells and in SNr neurons are eliminated (Yamada et al., 2001; Suzuki et al., 2002).

We therefore compared the $\beta \mathrm{HB}$-induced slowing effect in wild-type BL6 mice, in Kir6.2 knock-out mice, and in the heterozygous littermates of the knock-outs. We found that $\mathrm{SNr}$ GABAergic neurons from wild-type and heterozygous Kir6.2 $(+/-)$ mice exhibited a normal slowing with application of $\beta \mathrm{HB}$ or acetoacetate, but that the effect was completely absent in the Kir6.2 (-/-) mice (Fig. 3; supplemental Fig. 2, available at www.jneurosci.org as supplemental material). This result argues for the involvement of surface $\mathrm{K}_{\mathrm{ATP}}$ channels rather than mitoK $\mathrm{K}_{\mathrm{ATP}}$ channels in the effects of ketone bodies on firing rate.

\section{Are $\mathrm{K}_{\mathrm{ATP}}$ channels opening after ketone body application?}

Our data suggested that $\mathrm{K}_{\mathrm{ATP}}$ channels are required for the ketone body effect, and in particular that $\mathrm{K}_{\mathrm{ATP}}$ channels, opening in response to ketone body application, produce the slower firing rate of the $\mathrm{SNr}$ neurons. These neurons have very high input resistances (Richards et al., 1997), so that even a small increase in $\mathrm{K}^{+}$conductance could slow their firing rates. Rather than make an error-prone determination of input conductance over a long experiment with ketone body application, we thought that a straightforward way to implicate $\mathrm{K}_{\mathrm{ATP}}$ channels in the effect would be to apply glibenclamide or tolbutamide to neurons that had previously been incubated in $\beta \mathrm{HB}$. We would then expect to see a rapid increase in the firing rate, which we knew did not occur under control conditions.

Surprisingly, we did not observe any increase in firing rate on applying these sulfonylurea inhibitors to neurons previously incubated in $\beta \mathrm{HB}$, either on a short time scale (Fig. 4) or on a longer time scale of 30-40 min. In other words, previous application of sulfonylureas is capable of preventing the ketone body effect (as is the knock-out), but sulfonylureas cannot reverse the effect, even on the time scale on which removal of ketone bodies can reverse the effect. We considered two possible explanations for this outcome. One is that the $\mathrm{K}_{\mathrm{ATP}}$ channels are somehow required at an early step to set the ketone body effect in motion, but once this is done, they are no longer needed. This would also require that the

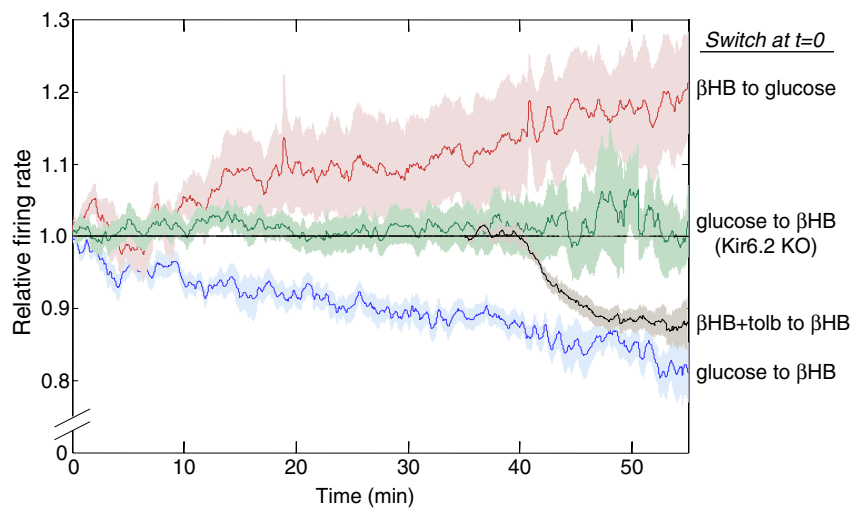

Figure 5. Time course of firing rate changes with ketone body application and with tolbutamide (tolb) washout. A switch of metabolites (glucose to glucose plus $\beta H B$ or the reverse switch for the red trace) occurred at time zero. The firing rate of individual cells, normalized to their control value (5 min average), was averaged to give the mean trace and SEM (shaded zone). Data are shown for the forward switch under control conditions (blue), for the reverse switch (red), and for the forward switch in slices from Kir6.2 (-/-) knock-out (KO) animals (green). The black trace is from slices placed in glucose ( $12 \mathrm{~mm})$ and tolbutamide $(200 \mu \mathrm{m})$ at $-15 \mathrm{~min}$, then switched to glucose (12 mm) plus $\beta \mathrm{HB}(2 \mathrm{~mm})$ plus tolbutamide $(200 \mu \mathrm{m})$ at time zero. Recordings began in glucose plus $\beta \mathrm{HB}$ plus tolbutamide at or before $30 \mathrm{~min}$, and then a switch to glucose plus $\beta \mathrm{HB}$ occurred at $35 \mathrm{~min}$. After a lag for the perfusion delay and tolbutamide washout, the firing rate quickly falls to approximately the rate seen for the ordinary forward switch. Numbers of experiments contributing to each trace (with smallest $n$ at latest time points) are as follows: blue, $n=8-15$; red, $n=7$; green, $n=9-16$; and black, $n=$ $12-29$.

ability of ketone bodies to sustain the effect is somehow $\mathrm{K}_{\mathrm{ATP}}$ independent.

The other explanation is that ketone body application and opening of $\mathrm{K}_{\mathrm{ATP}}$ channels produces a subsequent sulfonylurea insensitivity of the $\mathrm{K}_{\mathrm{ATP}}$ channels. There are precedents for such a loss of sulfonylurea sensitivity. Sulfonylurea sensitivity of $\mathrm{K}_{\mathrm{ATP}}$ channels can vary greatly between different cells expressing identical Kir6 and SUR subtypes and can vary with physiological changes in negatively charged lipids (Koster et al., 1999; Krauter et al., 2001), metabolic stress (Findlay, 1993), reactive oxygen species (Krippeit-Drews et al., 1999), intracellular $\mathrm{Ca}^{2+}$ (Koriyama et al., 2001), cytoskeletal disruption (Brady et al., 1996), or nucleotide levels (Brady et al., 1998). Ketone bodies could alter one of these parameters (in parallel with ATP production) to produce blocker insensitivity.

Based on this possibility, we performed a variation on the acute sulfonylurea wash-in experiment: we applied tolbutamide both before and during presentation of $\beta \mathrm{HB}$ and then recorded neuronal firing rate during acute washout of tolbutamide. If all of the conditions for $\mathrm{K}_{\mathrm{ATP}}$ opening are produced during $\beta \mathrm{HB}$ application, but the channels are prevented from opening by the constant presence of tolbutamide, then tolbutamide washout should lead to a rapid activation of $\mathrm{K}_{\mathrm{ATP}}$ channels and a slowing of the firing rate. Indeed, washout of tolbutamide under these conditions leads to a slower firing rate in the presence of $\beta \mathrm{HB}$, comparable with the slower firing seen after a direct switch into $\beta \mathrm{HB}$ but occurring much more promptly (Fig. 5, black trace). This result supports the conclusion that the slower firing is caused by $\mathrm{K}_{\mathrm{ATP}}$ opening induced by the metabolism of ketone bodies.

\section{$\mathrm{GABA}_{\mathrm{B}}$ signaling is also important for the ketone-body} induced slowing

Our initial experiments used kynurenate to block fast synaptic responses to glutamate and picrotoxin to block fast responses to 
GABA, but slower responses through metabotropic receptors were not blocked. It seemed particularly important to investigate the role of these pathways given the possibility that $\mathrm{K}_{\mathrm{ATP}}$ channels might be acting at an early step in the $\beta \mathrm{HB}$-induced slowing.

We tested an array of metabotropic receptor blockers acting on mGluR, dopamine, and $\mathrm{GABA}_{\mathrm{B}}$ receptors. Only the $\mathrm{GABA}_{\mathrm{B}}{ }^{-}$ selective compound CGP55845 blocked the firing rate effect of a switch from glucose alone to $\beta \mathrm{HB}$. This effect was seen both at concentrations of $2 \mu \mathrm{M}$ and $200 \mathrm{nM}$, making it likely that it was caused by a specific blockade of $\mathrm{GABA}_{\mathrm{B}}$ receptors.

We found that blockade of $\mathrm{GABA}_{\mathrm{B}}$ receptors by CGP55845 could prevent the slowing effect of a metabolic switch when applied in advance and could also reverse the effect promptly when applied after the slowing had occurred (Fig. 4), showing that $\mathrm{GABA}_{\mathrm{B}}$ activation is required for the effect. This effect of $\mathrm{GABA}_{\mathrm{B}}$ blockers is also dependent on $\mathrm{K}_{\mathrm{ATP}}$ channels, as previous blockade with glibenclamide or genetic knock-out of Kir6.2 prevented the faster firing produced by CGP55845 application in the presence of $\beta \mathrm{HB}$.

Ketone body metabolism has been proposed to increase GABA synthesis in neurons (Yudkoff et al., 2001) by changing the distribution of metabolic precursors. This could augment existing GABA signaling pathways by, for instance, increasing vesicular content of GABA. Such an effect might improve neuronal inhibition through both $\mathrm{GABA}_{\mathrm{A}}$ and $\mathrm{GABA}_{\mathrm{B}}$ receptors and lead to a slower firing rate, but it would not be predicted to depend on $\mathrm{K}_{\mathrm{ATP}}$ channels as does the ketone body effect studied here. Indeed, responses to the $\mathrm{GABA}_{\mathrm{B}}$ agonist baclofen are substantial in these neurons even in the presence of $\mathrm{K}_{\mathrm{ATP}}$ blockers or in the Kir6.2 knock-out (data not shown). We also found that the effect of ketone bodies was not altered in the absence of picrotoxin, as might be expected if $\mathrm{GABA}_{\mathrm{A}}$ signaling were enhanced by the ketone bodies.

\section{Discussion}

\section{Ketone bodies reduce the firing rate of $\mathrm{SNr}$ neurons by opening $\mathrm{K}_{\mathrm{ATP}}$ channels}

Our data show that the effect of ketone bodies on SNr neurons is to slow their firing rate, even when fast synaptic transmission is blocked. This effect requires the presence of both functional $\mathrm{K}_{\mathrm{ATP}}$ channels and intact $\mathrm{GABA}_{\mathrm{B}}$ signaling. What is the relationship between ketone bodies, $\mathrm{K}_{\mathrm{ATP}}$ channels, and GABA signaling?

$\mathrm{K}_{\mathrm{ATP}}$ channels are required for the effects of ketone bodies on firing rate, and our results argue that $\mathrm{K}_{\mathrm{ATP}}$ channels are opened rather than closed by ketone bodies. Application of sulfonylurea inhibitors of $\mathrm{K}_{\mathrm{ATP}}$ channels prevents but does not mimic the effect of ketone bodies (Figs. 3, 4; supplemental Fig. 1, available at www.jneurosci.org as supplemental material), whereas release of blockade by tolbutamide washout allows the effect to occur quickly (Fig. 5).

To explain the requirement for both $\mathrm{K}_{\mathrm{ATP}}$ channels and $\mathrm{GABA}_{\mathrm{B}}$ receptors, one possibility is that opening of $\mathrm{K}_{\mathrm{ATP}}$ channels promotes $\mathrm{GABA}_{\mathrm{B}}$ inhibition of $\mathrm{SNr}$ neuron firing. Presynaptic $\mathrm{K}_{\mathrm{ATP}}$ responses have been described in the $\mathrm{SNr}$ (Stanford and Lacey, 1996), although a first-order effect (opening of presynaptic $\mathrm{K}_{\mathrm{ATP}}$ channels) would decrease rather than increase $\mathrm{GABA}_{\mathrm{B}}$ release onto $\mathrm{SNr}$ neurons. In principle, a second-order presynaptic effect (decreased inhibition of the immediate presynaptic release) would have the correct sign. Alternatively, it might be that tonic $\mathrm{GABA}_{\mathrm{B}}$ signaling is required for the opening of $\mathrm{K}_{\mathrm{ATP}}$ channels in SNr neurons. There have been several reports of $\mathrm{K}_{\mathrm{ATP}}$ channel activation by G-proteins and G-protein-coupled receptors (Terzic et al., 1994; Sanchez et al., 1998; Smith et al., 2001), including activation by $\mathrm{GABA}_{\mathrm{B}}$ receptors in central neurons (Roeper et al., 1990; Mironov and Richter, 2000). Some level of $\mathrm{GABA}_{\mathrm{B}}$ tone could be important for establishing the set-point for $\mathrm{K}_{\mathrm{ATP}}$ activation, either by direct $\mathrm{G}$-protein modulation or perhaps by modulating the level of phosphoinositide lipids that are known to influence $\mathrm{K}_{\text {ATP }}$ opening (Baukrowitz et al., 1998; Shyng and Nichols, 1998).

\section{Ketone bodies, glycolysis, and $\mathrm{K}_{\mathrm{ATP}}$ channels: a hypothesis}

Why would ketone body metabolism lead to opening of $\mathrm{K}_{\mathrm{ATP}}$ channels? In ketosis, ketone bodies can partially or mostly replace glucose as a fuel for the brain; in early experiments on fasted humans, ketone body utilization replaced $\sim 60 \%$ of glucose utilization (Owen et al., 1967).

Early studies on the ketogenic diet in rodents (Appleton and DeVivo, 1974; DeVivo et al., 1978) found that in whole-brain extracts, the levels of substrates in the glycolytic pathway are altered, consistent with reduced utilization of glucose for energy. This fits with the classical understanding of the regulation of glycolysis. Ketone bodies are metabolized directly in mitochondria by oxidation in the tricarboxylic acid cycle, and oxidative metabolism is known to downregulate glycolysis through modulation of a key glycolytic enzyme, phosphofructokinase I.

Altered glycolysis is thus the main difference between metabolism of glucose and metabolism of ketone bodies. Although glycolysis produces only two of the $\sim 30$ net ATP molecules derived from the total oxidation of glucose, effective compartmentation of ATP may allow this glycolytically derived ATP to play a privileged role in controlling (Weiss and Lamp, 1989; Dubinsky et al., 1998) and fueling (Proverbio and Hoffman, 1977; Mercer and Dunham, 1981) processes in the plasma membrane [but this remains controversial (Knopp et al., 2001)]. Also, glycolytic enzymes can be closely associated with $\mathrm{K}_{\mathrm{ATP}}$ channels, which may support compartmentation or even provide a direct pathway by which glycolysis can regulate the channels (Dubinsky et al., 1998; Dhar-Chowdhury et al., 2005).

A ketone body-induced reduction in glycolytic production of ATP could activate $\mathrm{K}_{\text {ATP }}$ channels and depress excitability, particularly when electrical activity is high. Reduced synthesis of ATP in the submembrane compartment could lower the [ATP] (and raise $[\mathrm{ADP}]$ ) enough to open some fraction of the plasma membrane $\mathrm{K}_{\mathrm{ATP}}$ channels. The local [ATP] should depend on the synthesis rate, on diffusion between this compartment and the rest of the cell, and on the ATP consumption (Fig. 6). The principal consumer of ATP at the plasma membrane is the $\mathrm{Na}^{+}$pump $\left(\mathrm{Na}^{+}, \mathrm{K}^{+}\right.$-ATPase), which is responsible for pumping out the $\mathrm{Na}^{+}$that enters the neuron through cotransporters (such as those involved in neurotransmitter reuptake) and through the voltage-dependent $\mathrm{Na}^{+}$channels that produce action potential firing. Activity leading to greater pumping has been demonstrated to produce $\mathrm{K}_{\mathrm{ATP}}$ activation in several preparations, including central neurons (Kabakov, 1998; Nguyen et al., 2000; Haller et al., 2001). This direct connection between the level of electrical activity and ATP consumption at the membrane makes $\mathrm{K}_{\mathrm{ATP}}$ channels ideal for an anticonvulsant role and predicts a correlation between the strength of the ketone body effect and the initial rate of firing, as we observed (Fig. 2). We propose that the ketogenic diet may work as an epilepsy treatment because by reducing glycolytic ATP production, it lowers the level of electrical activity required to trigger this natural protective mechanism.

This hypothesis makes a simple connection between the known effects of ketone body metabolism on glycolysis, the effects of glycolysis on $\mathrm{K}_{\mathrm{ATP}}$ channels, and the effects of $\mathrm{Na}^{+}$pump 


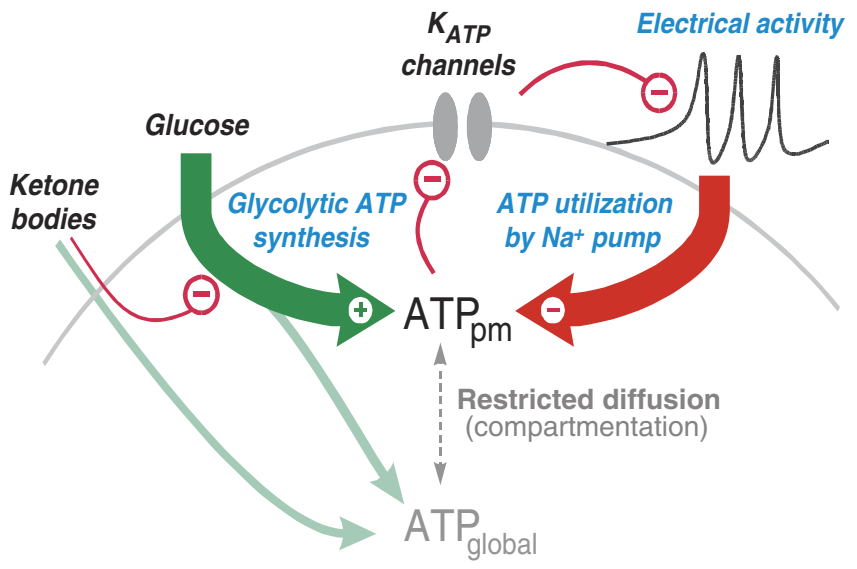

Figure 6. Hypothesis for the anticonvulsant effect of ketone body metabolism. Metabolism of ketone bodies raises global ATP but reduces glycolysis and glycolytic ATP synthesis. The reduction in $[A T P]$ near the plasma membrane $\left(\right.$ ATP $_{\mathrm{pm}}$ ) can disinhibit $\mathrm{K}_{\mathrm{ATP}}$ channels and thus reduce electrical activity. High electrical activity (as in a seizure) increases $\mathrm{Na}^{+}$influx and thus $\mathrm{Na}^{+}$pump activity and ATP utilization near the plasma membrane. This produces negative feedback on activity through the $K_{\text {ATP }}$ channels. The set-point at which this negative feedback safety mechanism becomes active is determined by the level of glycolytic ATP synthesis.

activity on $\mathrm{K}_{\mathrm{ATP}}$ channels. It provides a potential explanation for both the basic ketone body effect and for its dependence on firing rate.

The insensitivity of the ketone body response to sulfonylurea wash-in, once the effect has been established, may also indicate the presence of other mechanisms by which ketone body metabolism can modulate $\mathrm{K}_{\mathrm{ATP}}$ channels. However, the finding that channels remain closed as long as tolbutamide remains present, even in the presence of $\mathrm{R}-\beta \mathrm{HB}$, could also mean that channel opening per se is required (and perhaps sufficient) for the acquisition of blocker insensitivity.

A direct pharmacologic effect of ketone bodies on $\mathrm{K}_{\mathrm{ATP}}$ channels seems unlikely, given the slow time course of the effects.

\section{Ketone body effects on firing as a candidate mechanism for the ketogenic diet}

Our results indicate that the physiological ketone bodies, $\beta \mathrm{HB}$ and acetoacetate, can slow the firing of central neurons. The speed of this effect, its enhancement by high firing rate, and its presence in $\mathrm{SNr}$ neurons make it an excellent candidate mechanism for participating in the antiseizure effects of the ketogenic diet treatment.

The idea that reducing firing of inhibitory $\mathrm{SNr}$ neurons would be anticonvulsant seems counterintuitive, but it is well established that inhibitory neurons can participate in neuronal networks to produce synchronization and hyperactivity. The activity of SNr neurons in particular has been positively correlated with seizure activity and generalization (Bonhaus et al., 1986; Deransart et al., 2003). It is also established that suppressing the activity of these neurons can be anticonvulsant (Iadarola and Gale, 1982), although this effect depends on the site of antagonist injection and also on animal age (Velišková and Moshé, 2006).

The activity-dependent effect of ketone bodies on neuronal firing may also be more general, as a large number of central neurons express $\mathrm{K}_{\mathrm{ATP}}$ channels (Karschin et al., 1997; DunnMeynell et al., 1998; Zawar et al., 1999). For the most part the physiologic role of these channels is unknown, although they have been proposed to play a protective role in anoxia [for instance, in anoxia-induced seizures (Yamada et al., 2001)]. In re- spiratory neurons, it has been shown that $\mathrm{K}_{\mathrm{ATP}}$ channels can be activated in response to ATP consumption during normal burst firing (Haller et al., 2001). We suggest that widespread $\mathrm{K}_{\mathrm{ATP}}$ channels in central neurons may play a generally protective role in conditions of high neuronal firing, such as in epileptic seizures, and that this protective role is enhanced by the metabolism of ketone bodies and the restriction of glycolysis that occurs during dietary treatment for epilepsy.

\section{Relationship to other hypotheses about the ketogenic diet}

The dramatic alteration of food intake with the ketogenic diet produces pervasive physiological changes that are likely to activate multiple mechanisms to reduce seizures (Schwartzkroin, 1999). In addition to changing the fuel molecules used by neurons and glia in the brain, there may be changes in amino acid metabolism (Yudkoff et al., 2001), endocrine signaling, circulating lipids [which may themselves affect $\mathrm{K}_{\mathrm{ATP}}$ channels (Branstrom et al., 1997; Vamecq et al., 2005)], and other factors.

Inhibition of glycolysis by the ketogenic diet was found in the early biochemical work of DeVivo et al. (1978). The importance of glycolytic inhibition in the mechanism of the diet is supported by the success of caloric restriction studies in animals (Greene et al., 2001) and by the success of a modified dietary therapy in humans, the Low Glycemic Index Treatment (Pfeifer and Thiele, 2005). Although neither of these manipulations produces as large increases in circulating ketone bodies as are seen on the ketogenic diet, both may moderate or limit the rate of glycolysis. GarrigaCanut et al. (2006) recently reported that treatment with the glycolytic inhibitor 2-deoxyglucose could increase seizure threshold acutely and delay the progression of epileptic kindling in rats and argued for a role of glycolytically derived NADH in the regulation of gene expression by the chromatin-remodeling factor NRSF/REST. Changes in gene expression could certainly alter excitability chronically, as well as the progression of kindling. Perhaps the more acute effect of glycolytic inhibition on seizure threshold and the prompt reversal of seizure protection by sugar are explained by the actions of $\mathrm{K}_{\mathrm{ATP}}$ channels observed here.

\section{References}

Appleton DB, DeVivo DC (1974) An animal model for the ketogenic diet. Epilepsia 15:211-227.

Ashcroft FM, Gribble FM (1999) ATP-sensitive $\mathrm{K}^{+}$channels and insulin secretion: their role in health and disease. Diabetologia 42:903-919.

Bailey EE, Pfeifer HH, Thiele EA (2005) The use of diet in the treatment of epilepsy. Epilepsy Behav 6:4-8.

Baukrowitz T, Schulte U, Oliver D, Herlitze S, Krauter T, Tucker SJ, Ruppersberg JP, Fakler B (1998) PIP $_{2}$ and PIP as determinants for ATP inhibition of $\mathrm{K}_{\text {ATP }}$ channels. Science 282:1141-1144.

Bonhaus DW, Walters JR, McNamara JO (1986) Activation of substantia nigra neurons: role in the propagation of seizures in kindled rats. J Neurosci 6:3024-3030.

Brady PA, Alekseev AE, Aleksandrova LA, Gomez LA, Terzic A (1996) A disrupter of actin microfilaments impairs sulfonylurea-inhibitory gating of cardiac $\mathrm{K}_{\mathrm{ATP}}$ channels. Am J Physiol 271:H2710-H2716.

Brady PA, Alekseev AE, Terzic A (1998) Operative condition-dependent response of cardiac ATP-sensitive $\mathrm{K}^{+}$channels toward sulfonylureas. Circ Res 82:272-278.

Branstrom R, Corkey BE, Berggren PO, Larsson O (1997) Evidence for a unique long chain acyl-CoA ester binding site on the ATP-regulated potassium channel in mouse pancreatic beta cells. J Biol Chem 272:17390-17394.

Carpenter L, Halestrap AP (1994) The kinetics, substrate and inhibitor specificity of the lactate transporter of Ehrlich-Lettre tumour cells studied with the intracellular pH indicator BCECF. Biochem J 304:751-760.

Cullingford TE, Eagles DA, Sato H (2002) The ketogenic diet upregulates expression of the gene encoding the key ketogenic enzyme mitochondrial 
3-hydroxy-3-methylglutaryl-CoA synthase in rat brain. Epilepsy Res 49:99-107.

Depaulis A, Vergnes M, Marescaux C (1994) Endogenous control of epilepsy: the nigral inhibitory system. Prog Neurobiol 42:33-52.

Deransart C, Hellwig B, Heupel-Reuter M, Leger JF, Heck D, Lücking CH (2003) Single-unit analysis of substantia nigra pars reticulata neurons in freely behaving rats with genetic absence epilepsy. Epilepsia 44:1513-1520.

DeVivo DC, Leckie MP, Ferrendelli JS, McDougal Jr DB (1978) Chronic ketosis and cerebral metabolism. Ann Neurol 3:331-337.

Dhar-Chowdhury P, Harrell MD, Han SY, Jankowska D, Parachuru L, Morrissey A, Srivastava S, Liu W, Malester B, Yoshida H, Coetzee WA (2005) The glycolytic enzymes, glyceraldehyde-3-phosphate dehydrogenase, triose-phosphate isomerase, and pyruvate kinase are components of the $\mathrm{K}_{\mathrm{ATP}}$ channel macromolecular complex and regulate its function. J Biol Chem 280:38464-38470.

Dubinsky WP, Mayorga-Wark O, Schultz SG (1998) Colocalization of glycolytic enzyme activity and KATP channels in basolateral membrane of Necturus enterocytes. Am J Physiol 275:C1653-C1659.

Dunn-Meynell AA, Rawson NE, Levin BE (1998) Distribution and phenotype of neurons containing the ATP-sensitive $\mathrm{K}+$ channel in rat brain. Brain Res 814:41-54.

Findlay I (1993) Sulphonylurea drugs no longer inhibit ATP-sensitive $\mathrm{K}^{+}$ channels during metabolic stress in cardiac muscle. J Pharmacol Exp Ther 266:456-467.

Freeman JM, Freeman JB, Kelly MT (2000) The ketogenic diet: treatment for epilepsy. New York: Demos.

Gale K (1986) Role of the substantia nigra in GABA-mediated anticonvulsant actions. Adv Neurol 44:343-364.

Garriga-Canut M, Schoenike B, Qazi R, Bergendahl K, Daley TJ, Pfender RM, Morrison JF, Ockuly J, Stafstrom C, Sutula T, Roopra A (2006) 2-Deoxy-D-glucose reduces epilepsy progression by NRSF-CtBPdependent metabolic regulation of chromatin structure. Nat Neurosci 9:1382-1387.

Greene AE, Todorova MT, McGowan R, Seyfried TN (2001) Caloric restriction inhibits seizure susceptibility in epileptic EL mice by reducing blood glucose. Epilepsia 42:1371-1378.

Hall LM (1962) Preparation of crystalline lithium acetoacetate. Anal Biochem 3:75-80.

Haller M, Mironov SL, Karschin A, Richter DW (2001) Dynamic activation of $\mathrm{K}_{\mathrm{ATP}}$ channels in rhythmically active neurons. J Physiol (Lond) 537:69-81.

Hanley PJ, Mickel M, Loffler M, Brandt U, Daut J (2002) $\mathrm{K}_{\text {ATP }}$ channelindependent targets of diazoxide and 5-hydroxydecanoate in the heart. J Physiol (Lond) 542:735-741.

Huttenlocher PR (1976) Ketonemia and seizures: metabolic and anticonvulsant effects of two ketogenic diets in childhood epilepsy. Pediatr Res 10:536-540.

Iadarola MJ, Gale K (1982) Substantia nigra: site of anticonvulsant activity mediated by gamma-aminobutyric acid. Science 218:1237-1240.

Izumi Y, Ishii K, Katsuki H, Benz AM, Zorumski CF (1998) BetaHydroxybutyrate fuels synaptic function during development. Histological and physiological evidence in rat hippocampal slices. J Clin Invest 101:1121-1132.

Jaburek M, Yarov-Yarovoy V, Paucek P, Garlid KD (1998) State-dependent inhibition of the mitochondrial KATP channel by glyburide and 5-hydroxydecanoate. J Biol Chem 273:13578-13582.

Jackson VN, Halestrap AP (1996) The kinetics, substrate, and inhibitor specificity of the monocarboxylate (lactate) transporter of rat liver cells determined using the fluorescent intracellular $\mathrm{pH}$ indicator, $2^{\prime}, 7^{\prime}$ bis(carboxyethyl)-5(6)-carboxyfluorescein. J Biol Chem 271:861-868.

Kabakov AY (1998) Activation of $\mathrm{K}_{\mathrm{ATP}}$ channels by Na/K pump in isolated cardiac myocytes and giant membrane patches. Biophys J 75:2858-2867.

Karschin C, Ecke C, Ashcroft FM, Karschin A (1997) Overlapping distribution of $\mathrm{K}_{\mathrm{ATP}}$ channel-forming Kir6.2 subunit and the sulfonylurea receptor SUR1 in rodent brain. FEBS Lett 401:59-64.

Knopp A, Thierfelder S, Doepner B, Benndorf K (2001) Mitochondria are the main ATP source for a cytosolic pool controlling the activity of ATPsensitive $\mathrm{K}^{+}$channels in mouse cardiac myocytes. Cardiovasc Res 52:236-245.

Koriyama N, Kakei M, Nakazaki M, Yaekura K, Hashiguchi H, Aso K, Fukudome M, Yada T, Ito S, Tei C (2001) Free radical-mediated tolbutamide desensitization of $\mathrm{K}_{\mathrm{ATP}}$ channels in rat pancreatic beta-cells. Endocr J 48:337-344.

Koster JC, Sha Q, Nichols CG (1999) Sulfonylurea and $\mathrm{K}^{+}$-channel opener sensitivity of $\mathrm{K}_{\mathrm{ATP}}$ channels. Functional coupling of Kir6.2 and SUR1 subunits. J Gen Physiol 114:203-213.

Krauter T, Ruppersberg JP, Baukrowitz T (2001) Phospholipids as modulators of $K_{\text {ATP }}$ channels: distinct mechanisms for control of sensitivity to sulphonylureas, $\mathrm{K}^{+}$channel openers, and ATP. Mol Pharmacol 59:1086-1093.

Krippeit-Drews P, Kramer C, Welker S, Lang F, Ammon HP, Drews G (1999) Interference of $\mathrm{H}_{2} \mathrm{O}_{2}$ with stimulus-secretion coupling in mouse pancreatic beta-cells. J Physiol (Lond) 514:471-481.

Liss B, Bruns R, Roeper J (1999) Alternative sulfonylurea receptor expression defines metabolic sensitivity of $\mathrm{K}_{\mathrm{ATP}}$ channels in dopaminergic midbrain neurons. EMBO J 18:833-846.

Macdonald RL, Kelly KM (1995) Antiepileptic drug mechanisms of action. Epilepsia 36 [Suppl 2]:S2-S12.

McNamara JO, Galloway MT, Rigsbee LC, Shin C (1984) Evidence implicating substantia nigra in regulation of kindled seizure threshold. J Neurosci 4:2410-2417.

Mercer RW, Dunham PB (1981) Membrane-bound ATP fuels the Na/K pump. Studies on membrane-bound glycolytic enzymes on inside-out vesicles from human red cell membranes. J Gen Physiol 78:547-568.

Mironov SL, Richter DW (2000) Intracellular signalling pathways modulate $\mathrm{K}_{\mathrm{ATP}}$ channels in inspiratory brainstem neurones and their hypoxic activation: involvement of metabotropic receptors, G-proteins and cytoskeleton. Brain Res 853:60-67.

Nehlig A (1999) Age-dependent pathways of brain energy metabolism: the suckling rat, a natural model of the ketogenic diet. Epilepsy Res 37:211-221.

Nguyen TS, Winn HR, Janigro D (2000) ATP-sensitive potassium channels may participate in the coupling of neuronal activity and cerebrovascular tone. Am J Physiol Heart Circ Physiol 278:H878-H885.

Nordli DR, DeVivo DC (1997) The ketogenic diet revisited: back to the future. Epilepsia 38:743-749.

Owen OE, Morgan AP, Kemp HG, Sullivan JM, Herrera MG, Cahill Jr GF (1967) Brain metabolism during fasting. J Clin Invest 46:1589-1595.

Pan JW, Telang FW, Lee JH, de Graaf RA, Rothman DL, Stein DT, Hetherington HP (2001) Measurement of beta-hydroxybutyrate in acute hyperketonemia in human brain. J Neurochem 79:539-544.

Peterman MG (1924) Ketogenic diet in treatment of epilepsy. Am J Dis Child 28:28-33.

Pfeifer HH, Thiele EA (2005) Low-glycemic-index treatment: a liberalized ketogenic diet for treatment of intractable epilepsy. Neurology 65:1810-1812.

Proverbio F, Hoffman JF (1977) Membrane compartmentalized ATP and its preferential use by the Na,K-ATPase of human red cell ghosts. J Gen Physiol 69:605-632.

Richards CD, Shiroyama T, Kitai ST (1997) Electrophysiological and immunocytochemical characterization of GABA and dopamine neurons in the substantia nigra of the rat. Neuroscience 80:545-557.

Roeper J, Hainsworth AH, Ashcroft FM (1990) Tolbutamide reverses membrane hyperpolarisation induced by activation of D2 receptors and $\mathrm{GABA}_{\mathrm{B}}$ receptors in isolated substantia nigra neurones. Pflügers Arch 416:473-475.

Sanchez JA, Gonoi T, Inagaki N, Katada T, Seino S (1998) Modulation of reconstituted ATP-sensitive $\mathrm{K}^{+}$-channels by GTP-binding proteins in a mammalian cell line. J Physiol (Lond) 507:315-324.

Schwartzkroin PA (1999) Mechanisms underlying the anti-epileptic efficacy of the ketogenic diet. Epilepsy Res 37:171-180.

Seino S, Iwanaga T, Nagashima K, Miki T (2000) Diverse roles of $K_{\text {ATP }}$ channels learned from Kir6.2 genetically engineered mice. Diabetes 49:311-318.

Shyng SL, Nichols CG (1998) Membrane phospholipid control of nucleotide sensitivity of $\mathrm{K}_{\mathrm{ATP}}$ channels. Science 282:1138-1141.

Smith PA, Sellers LA, Humphrey PP (2001) Somatostatin activates two types of inwardly rectifying $\mathrm{K}^{+}$channels in MIN-6 cells. J Physiol (Lond) 532:127-142.

Stanford IM, Lacey MG (1996) Electrophysiological investigation of adenosine trisphosphate-sensitive potassium channels in the rat substantia nigra pars reticulata. Neuroscience 74:499-509.

Suzuki M, Sasaki N, Miki T, Sakamoto N, Ohmoto-Sekine Y, Tamagawa M, 
Seino S, Marban E, Nakaya H (2002) Role of sarcolemmal $\mathrm{K}_{\mathrm{ATP}}$ channels in cardioprotection against ischemia/reperfusion injury in mice. J Clin Invest 109:509-516.

Terzic A, Tung RT, Inanobe A, Katada T, Kurachi Y (1994) G proteins activate ATP-sensitive $\mathrm{K}^{+}$channels by antagonizing ATP-dependent gating. Neuron 12:885-893.

Thiele EA (2003) Assessing the efficacy of antiepileptic treatments: the ketogenic diet. Epilepsia 44:26-29.

Thio LL, Wong M, Yamada KA (2000) Ketone bodies do not directly alter excitatory or inhibitory hippocampal synaptic transmission. Neurology 54:325-331.

Vamecq J, Vallee L, Lesage F, Gressens P, Stables JP (2005) Antiepileptic popular ketogenic diet: emerging twists in an ancient story. Prog Neurobiol 75:1-28.

Velíšková J, Moshé SL (2006) Update on the role of substantia nigra pars reticulata in the regulation of seizures. Epilepsy Curr 6:83-87.

Wang D, Pascual JM, Yang H, Engelstad K, Jhung S, Sun RP, De Vivo DC
(2005) Glut-1 deficiency syndrome: clinical, genetic, and therapeutic aspects. Ann Neurol 57:111-118.

Webber RJ, Edmond J (1977) Utilization of L(+)-3-hydroxybutyrate, D()-3-hydroxybutyrate, acetoacetate, and glucose for respiration and lipid synthesis in the 18-day-old rat. J Biol Chem 252:5222-5226.

Weiss JN, Lamp ST (1989) Cardiac ATP-sensitive $\mathrm{K}^{+}$channels. Evidence for preferential regulation by glycolysis. J Gen Physiol 94:911-935.

Wilder RM (1921) The effects of ketonemia on the course of epilepsy. Mayo Clin Bull 2:307.

Yamada K, Ji JJ, Yuan H, Miki T, Sato S, Horimoto N, Shimizu T, Seino S, Inagaki N (2001) Protective role of ATP-sensitive potassium channels in hypoxia-induced generalized seizure. Science 292:1543-1546.

Yudkoff M, Daikhin Y, Nissim I, Lazarow A, Nissim I (2001) Ketogenic diet, amino acid metabolism, and seizure control. J Neurosci Res 66:931-940.

Zawar C, Plant TD, Schirra C, Konnerth A, Neumcke B (1999) Cell-type specific expression of ATP-sensitive potassium channels in the rat hippocampus. J Physiol (Lond) 514:327-341. 